\title{
Reflections on the International Medical Society of Paraplegia and management of paraplegia
}

\author{
R Carter MD \\ President of the International Medical Society of Paraplegia; Professor of Clinical \\ Rehabilitation, Baylor College of Medicine; and Director, Spinal Cord Injury Program, \\ The Institute for Rehabilitation and Research, 1333 Moursund Avenue, Houston, Texas \\ 77030, USA.
}

In 1943, the British government decided to organize a new spinal unit at the Ministry of Pensions Hospital at Stoke Mandeville in Aylesbury as one of the medical preparations for the planned second front offensive in the spring of 1944. With the opening of this unit on February 1, 1944, a new era began for spinal cord sufferers when the concept of a comprehensive service for paraplegics and tetraplegics including all aspects of initial as well as long term treatment in rehabilitation was introduced. A neurosurgeon, Professor (subsequently Sir) Ludwig Guttmann, was chosen to be the director of this unit and in later years was knighted by the Queen for his primary efforts in the rehabilitation of spinal injured patients both military and civilian. The history of the early development of the management of spinal cord paralysis has been covered in an article entitled 'Development and care of spinal cord paralysis (1918-1986)' by Sir George Bedbrook. ${ }^{1}$

The second significant event was the founding of the Stoke Mandeville Wheelchair Games which started with wheelchair basketball in 1945 along with archery and table tennis. On July 28, 1948, the Stoke Mandeville Games officially began as the Summer Olympics, opened in London. The success of these games increased activities of competitive wheelchair sports, but above all increased the world's knowledge of the abilities of patients with spinal cord injuries. This fostered the formation of the International Sports Organization for the Disabled. The Stoke Mandeville Games became international in 1952 with Dutch participation, and were subsequently held in Rome in 1960, then in Tokyo, Tel Aviv, Heidelberg,
Holland, Toronto and Stoke Mandeville.

As years went by the need to form an international medical society of paraplegia became more and more manifest to team physicians who travelled from around the world with their spinal cord injury teams to the Stoke Mandeville Games. There was a desire to exchange the experience and knowledge of problems concerned with injuries and diseases of the spinal cord. Therefore, the International Medical Society of Paraplegia (IMSOP) was formally founded in 1960. Sir Ludwig Guttmann was the first president and was followed by Dr Herbert Talbot, Dr Albert Tricot, Professor Volkmar Paeslack, Sir George Bedbrook, Professor Alain Rossier and Dr R Edward Carter. By 1963, the Society achieved a major step towards its founding aim of increased worldwide communication concerning spinal cord injury management by publication of the journal, Paraplegia. The first issue was published in April 1963 with Sir Ludwig Guttmann as the first editor.

Sir Ludwig remained the first president until he was succeeded by $\mathrm{Dr}$ Herbert Talbot of the United States in 1969. Dr Jack Walsh initially functioned as secretary of the Society and the council with $\mathrm{Dr}$ Hans Frankel taking over in July, 1977. By then membership of the Society stood at 716. Dr John Young became the first corresponding secretary for the United States, and subsequent corresponding secretaries through the years have been appointed for Italy, Japan and Spain. The journal Paraplegia began with the publication of 4 issues per year. Meetings were to be held annually at Stoke Mandeville Hospital, except that every 4 years they were to be held along with the 
Wheelchair Olympics in the country of the Olympics. IMSOP became truly international in its selection of annual meeting sites, and began to rotate its meetings to different areas of the world while still meeting in conjunction with the Wheelchair Olympics every 4 years at that specific time and place. The annual general meeting usually returns to Stoke Mandeville Hospital approximately once every 4 years. It was also generally agreed that at least every 2 years the annual general meeting should be held in conjunction with a national professional group concerned with paraplegia. Gradually these national professional groups have arisen beginning with the American Spinal Injury Association and, continuing with the American Paralysis Association, the Japanese Medical Society of Paraplegia, the Indian Medical Society of Paraplegia, the Far East and South Pacific Group for the Study of Paraplegia, the German Paraplegia Society, the international French Speaking Spinal Cord Injury Study Group (AFIGAP), the Italian Paraplegic Society and the Scandanavian Medical Society of Paraplegia. Each of these have held national meetings and many of these meetings became regional meetings of IMSOP.

Sir Ludwig Guttmann died on March 18, 1980 and subsequently $\mathrm{Mr}$ Phillip Harris became the new editor of Paraplegia. An editorial board was established in the early 1980s. Mr Phillip Harris of Edinburgh, the current editor of Paraplegia, has been responsible for much of its excellence, organization and expansion. In 1990, the journal went from 6 issues to 9 issues annually and, beginning in January 1992, its publishing house has changed to that of The Macmillan Press Ltd and there will be 12 issues published annually.

Mr K Krishnan of Southport kindly presented the Society with its official presidential chain of office. The names of the Society's presidents are engraved on clips on the ribbons supporting the medal.

Through the generosity of the Swiss Fund, much progress was made in transmitting information on the management of spinal cord injury to developing countries. Paraplegia has been subsidized and is sent to many centers in the Far East, Africa and South America. In addition to covering journal subscriptions, selected subsidies for transportation and expenses for physicians from these countries to attend the annual scientific meeting of IMSOP were also instigated. Research fellowships that can be awarded for up to 3 months at any leading spinal center have also been made available to individual physicians applying from developing countries. In 1987, the silver jubilee issue of Paraplegia was published, and the contents included a summary of the history of IMSOP entitled 'The International Medical Society of Paraplegia at a glance' written by the then president, Professor Alain Rossier; ${ }^{2}$ there were also profiles of Phillip Harris and James Cosbie Ross, as well as a 'Historical review of paraplegia before 1918' by J T Hughes, ${ }^{3}$ and 'Development and care of spinal cord paralysis (1918 to 1986)' by Sir George Bedbrook. Another item of specific interest was the republishing of the foreword by Sir Ludwig Guttmann that had been published in Volume 1, Number 1 of Paraplegia.

IMSOP is now also recognized by the World Health Organization as a nongovernmental organization.

In 1975, the council of the Society decided to originate the award of a silver medal to be presented at the annual meeting to a member who had made outstanding contributions to the field of paraplegia as well as to the International Society. The initial medals in 1975 and 1976 were awarded to Sir Ludwig Guttmann of the United Kingdom, and to Dr Ernest Bors of the United States. These were followed by awards to Dr L Michaelis of the United Kingdom, Sir George Bedbrook of Western Australia, Dr M Maury of France, Dr John Young of the United States, Dr Alan Hardy of the United Kingdom, Dr F W Meinecke of Germany, Dr H L Frankel of the United Kingdom, Dr Y Nakamura of Japan, Dr M Weiss of Poland, Mr P Harris of Scotland, Dr Harry Hahn of the United States, Professor Alain Rossier of Switzerland, Dr Al Jousse of Canada, Mr J Cosbie Ross of the United Kingdom, Dr Paul Dollfus of France and Dr R Edward Carter of the United States.

As we approach the thirtieth year of 
publication of Paraplegia, it is interesting to reflect on the numerous changes that have occurred in a relatively short period of time as well as the many challenges and opportunities that await us in the next several years. Paraplegia, well recognized internationally, has expanded from 4 issues to 6 , then 9 and on to 12 issues a year. By 1989, the Society membership had grown from several hundred to over one thousand members internationally. National paraplegic societies have proliferated and consideration is being given to the regular establishment of national issues of the journal containing the best of the national scientific papers. In addition, further liaison with the national societies may result in their formal representation on the council of IMSOP. Truly, the Society may become an international federation of national specialty societies, plus representation from developing countries, which will give it a balanced leadership. In addition, closer liaison is being developed between IMSOP and other international rehabilitation societies such as the International Rehabilitation Medicine Association, Rehabilitation International, the World Health Organization and others.

The management of spinal cord injury has been greatly refined and much emphasis has been placed on both primary and secondary prevention. The life span of the spinal cord injured which was measured in months at the end of World War II is now upwards of 25 to 30 years. With more and more survivors existing and rejoining their communities, there has been an increasing demand and a gradual reduction of architectural barriers along with a greater acceptance of wheelchair individuals in all aspects of life. Also, the ever growing number of survivors have pressured national governments to sponsor more research in neuroregeneration. The Society has dedicated at least one section of its annual program to updates in neuroregeneration research. This has fostered greater collaboration between basic researchers and clinicians.

Medical and surgical advances have been numerous. For example, the development of civilian training in cardiorespiratory resuscitation in the middle to late 1960s together with the establishment of respiratory therapy units and the improved quality of respirators resulted in increasing the survival of ventilator dependent tetraplegics. A significant management tool became available in the early 1970s through Dr William Glenn at Yale University in the development of electrophrenic respiration in properly selected candidates. The results in portability, safety and longevity of electrophrenic respiration have become quite significant. Another major advance consisted of research for appropriate materials for seating surfaces for the prevention of pressure ulcers. This is a very significant factor in the secondary prevention of complications. Another significant advance was the development of cystolithotripsy for the destruction of renal stones. This has obviated the necessity for surgery in many patients and has greatly reduced the morbidity and mortality from extensive and repetitive surgical procedures. Further research has been developed in the area of sexuality through the development of erections by either implantation, electrical stimulation or direct injection. Electrical stimulation has also been used for bladder emptying to prevent infection in the urinary tract. Functional electrical stimulation has been used more and more in many major research centers to affect standing and begin a research program into an electrically stimulated gait. A relatively new promising method of spasticity control when all medications fail has been the advent of the baclofen pump. This consists of a subcutaneous reservoir connected by a tube to the spinal canal for direct instillation of diluted solutions of antispasmodics to control severe spasms. In selected patients this has been shown to produce amazing results.

In the future, further studies will be forthcoming on the stimulation of neural regeneration immediately post trauma as well as later. The second major frontier is the control of pain in spinal cord injury. Although many parameters, methods and drugs have been tried, there is no one method that has a high degree of effectiveness. Finally, there is the area of practical and cost effective environmental control units for very high spinal cord injured 


\section{Carter}

patients to enable them to be better managed in the home environment and to participate in the community and workplace.

As mentioned previously, the challenges ahead are formidable, but with the increases in technology plus the participation of various medical and other specialists in coordinating their activities and planning their research, the next decade should be phenomenal.

\section{References}

1 Bedbrook GM (1987) The development and care of spinal cord paralysis (1918 to 1986). Paraplegia 25 (3): 172-184.

2 Rossier AB (1987) The International Medical Society of Paraplegia at a glance. Paraplegia 25 (3): $157-159$.

3 Hughes JT (1987) Historical review of paraplegia before 1918. Paraplegia 25 (3): 168-171. 